\title{
グラファイト系炭素の次元性と応用
}

Dimensionality and Applications of Various Graphite Carbons

\section{村上 睦明}

\author{
Mutsuaki MURAKAMI
}

\begin{abstract}
It reports on the advancement of a recent graphitized carbon material from the viewpoint of dimensionality and application. First of all, the dimensional change and the possible application of fullerene (zero-dimensional graphite), carbon nanotube (one-dimensional), and graphene (two-dimensional) are described. The synthesis of the unique graphite fiber is also mentioned, as an example of obtaining a graphitized material in various forms by the molecular structure of the raw material. Next, making of a high-quality graphite film from a polyimide and its optical and thermal applications are described. It introduces the research of the pressure-induced phase transition from the graphite film to diamond.

[graphite, dimensionality, fullerene, nanotube, graphene, thermal application, optical application, phase transition, diamond]
\end{abstract}

\section{1.はじめに}

近年, 炭素材料の研究は急速に進捗しており, 中 でもカーボンナノチューブやフラーレンを含むグラ ファイト系炭素はその優れた物性（高電気伝導度, 高電子移動度, 高耐熱性, 高熱伝導度, 等) のゆえ に 21 世紀の新素材としての期待が高まっている。 本報告では, 各種のグラファイト系炭素の次元性に 注目し，その作製と応用の観点から最近の進歩につ いて紹介する。

\section{2. 次元性による炭素の分類}

炭素材料の多様性は, 炭素原子が $s p^{3}, s p^{2}, s p$ 結 合のいずれの結合をも取り得る事による。 $s p^{3}$ 結合 からなるダイヤモンド, $s p^{2}$ 結合からなるグラファ イト, $s p$ 結合からなるカルビンは炭素の典型的同 素体であり，それぞれの結合様式に起因する三次元 的, 二次元的, 一次元的物性を持つ。Table 1 に示 す様に, この 3 種類の同素体についてはすでに固相, 液相, 気相から合成する方法が報告されている[1]。

カルビンは1968 年に発見され[2], 発見と構造の 提唱は早かったものの炭素の研究対象としては取り
残されている。カルビンの相図は気相，液相，ダイ ヤモンド，グラファイトに囲まれた狭い領域に存在 すると言われているが明確ではなく, 合成法, 物性, 結晶構造のいずれもまだ確立されたものではない。 研究が進まない理由は, 十分な大きさの結晶が得ら れない事, 多くの形態 $(\alpha-, \beta$-カルビン, チャオア イト等）が存在する事である。一方で有機化学者は ポリアセチレンの脱水素反応やポリ塩化ビニルの脱 塩素化反応，などからカルビン型高分子の合成に取 り組んで抢りこれからのカルビン研究には有機化 学者と高圧力研究者の密接な協力が必要であろう。

Table 1. Synthetic methods of carbon allotropes (Diamond, Graphite, Carbyne).

\begin{tabular}{|c|c|c|c|}
\hline & \multicolumn{3}{|c|}{ Method } \\
\hline & Solid Phase & Liquid Phase & Gas Phase \\
\hline Diamond & $\begin{array}{l}\text { Shock-wave conver- } \\
\text { sion, Heat treatment } \\
\text { under static pressure. }\end{array}$ & $\begin{array}{l}\text { Temperature } \\
\text { gradient method }\end{array}$ & $\begin{array}{l}\text { Plasma } \\
\text { method }\end{array}$ \\
\hline Graphite & $\begin{array}{l}\text { Heat treatment of } \\
\text { polymer }\end{array}$ & $\begin{array}{l}\text { Recrystallization } \\
\text { from melt metal }\end{array}$ & $\begin{array}{l}\text { Thermal } \\
\text { degradation } \\
\text { and deposition }\end{array}$ \\
\hline Carbyne & $\begin{array}{l}\text { Synthesis } \\
\text { (Chemical) }\end{array}$ & $\begin{array}{l}\text { Acetylene } \\
\text { polymerization }\end{array}$ & $\begin{array}{l}\text { Plasma } \\
\text { method }\end{array}$ \\
\hline
\end{tabular}

干566-0072 大阪府摂津市鳥飼西 5-1-1 株)カネカ エレクトロニクス研究所

Electronics Research Laboratories, KANEKA Corporation, 5-1-1 Torikai-nishi, Settsu, Osaka 566-0072

Electronic address: Mutsuaki_Murakami@kn.kaneka.co.jp 
グラファイト系炭素においても次元性からの分類 が可能である。すなわち，フラーレンを 0 次元とす れば, カーボンナノチューブは一次元, グラフェン （単層グラファイト）は二次元であると考えられる。 グラファイトは三次元構造を持つが物性は二次元的 であり, $a-b$ 面に沿って簡単に壁開でき, 単結晶 グラファイトの電気伝導度は面方向之面垂直方向之 で 5000 倍異なる。グラファイトは van der Waals 力 で弱く結合した層間に各種の原子や分子を挿入する 事が出来，その様な層間化合物の生成によってグラ ファイトの二次元的性質をより顕著に引き出す事が できる。この様な層間化合物の形成反応はリチウム 二次電池における陰極反応として広く用いられてい る。

\section{3. フラーレンの高分子化と応用}

フラーレンはその二重結合に種々の置換基の付加 が可能で, 高温, 高圧, 光, 電子線などの作用で比 較的簡単に重合する。すなわち，フラーレンから一 次元的炭素や二次元的炭素の合成が可能となる。例 えば，液一液界面析出法という極めて簡易な方法で フラーレンの高分子を得る事ができる[3]。これは $\mathrm{C}_{60}$ を飽和溶解させたトルエン溶液にイソプロピル アルコールを静かに注ぎ， $20^{\circ} \mathrm{C} て ゙$ 放置する事によっ て液一液界面にウィスカ状生成物を析出させるもの である。生成物の機械的強度は $\mathrm{C}_{60}$ 結晶よりも一桁 大きく, TEM 観察により成長軸方向に $\mathrm{C}_{60}$ の分子 中心間距離 $1.0 \mathrm{~nm}$ で最密充填している事が明らか になっている。この事から $\mathrm{C}_{60}$ 分子が $[2+2]$ 付加 環化重合によって一次元的に高分子化していると考 えられている。

エレクトロニクス分野でフラーレンの応用として 興味深いのは $\mathrm{N}$ 型半導体としての応用である。ポ リチオフェンやペンタセン等の有機半導体はフレキ シブル, 印刷可能, 低コスト化可能などの特徵を有 し，シリコンデバイス代わる有機 FET や太陽電池 としての期待が大きい。有機半導体は一般に $\mathrm{P}$ 型 半導体であるのに対して, $\mathrm{C}_{60}$ は数少ない $\mathrm{N}$ 型半導 体であり，エピタキシャルフィルムは $0.6 \mathrm{~cm}^{2} / V s$ の 移動度を有している。自己組織化により塗布するだ けで $\mathrm{C}_{60}$ 誘導体が一次元配向する材料が開発されて おり, $\mathrm{P}$ 型有機半導体との組み合わせで印刷可能な 太陽電池の開発が進んでいる $[4]$ 。現在, 薄膜有機 太陽電池の変換効率は数\%であるが，将来的にはシ
リコンを上回る高効率が期待できるとの指摘もあり， 今後の進渉が期待される。

\section{4. カーボンナノチューブとその応用}

カーボンナノチューブ（CNT）は近年活発に研究 されておりすでに膨大な報告がある。CNT はアー ク放電, レーザー蒸発法, 化学気相蒸着 (CVD) 法，等で合成されるが，合成時に純粋な黒鉛を使用 すればフラーレンが，原料に $\mathrm{La} や \mathrm{Sc}$ などの遷移 金属を添加すれば金属内包フラーレンが， Ni や Co を添加すれば CNT を含む気相成長炭素繊維が得ら れる。CNT の特徴はアスペクト比が極めて大きく, 柔軟で弾性に富み, 樹脂並みに軽く, 金属よりも電 気伝導性，熱伝導性に優れると言う点である。しか し，これらの特徵を備えた CNT を実用材料とする には，(1)大きさ・長さを制御する，(2)単層 CNT の みを作る, (3)キラリティ（金属的・半導体的 CNT の作り分け）を制御する，(4)バンドル（束）をほぐ す, (5)電極界面との物性を理解・制御する，等の技 術開発が必要となる。

最近，スーパーグロース法と名づけられた CNT の画期的な製造法が開発された $[5,6]$ 。これは水が CNT 成長触媒の活性発現亡維持に重要であると言 う発見に基づき，CVD 法を改良したものである。 この方法には，(1)単層 CNT のみが生成する，(2)太 さが均一 ( $\phi 3 \mathrm{~nm})$ である, (3)長さは 1 2 $\mathrm{mm}$ で あり従来の手法で得られる CNT $(10 \mu \mathrm{m}$ 程度) よ り極めて長い，(4)すすや触媒が少なく高純度である， (5)バンドルを形成しない, (6)高密度に生成する $\left(5 \times 10^{11}\right.$ 本 $\left./ \mathrm{cm}^{2}\right)$ ，等の特徵がある。これらの特徵は 実用化に向けての多くの技術課題を解決するもので ある。キラリティの制御は最も難しい製造技術で現 在でも金属 CNT と半導体 CNT を作り分ける事はで きない。しかし最近，金属と半導体の単層 CNT 混 合物を化学的に分離する技術が開発された[7]。こ れはアミンと金属 CNT の吸着エネルギーが半導体 的 CNT との吸着エネルギーより大きい事を利用す るものである。CNT とオクチルアミンを分散・溶 解させた THF 溶液を超音波処理しさらに遠心分離 を繰り返すと, 結果的に有機溶媒に溶解しやすいア ミンと金属 CNT が上澄み液中に残る。

実用的な観点からは CNT のバンドルをほぐして 完全分散させる事，電極界面との物性を理解・制御 する事は重要である。分散には超音波などの物理的 
手法や分散剂を用いる化学的方法があるが, CNT はアスペクト比が大きくその直径は可視光よりも短 いため，透明樹脂に完全分散できれば透明導電性フィ ルムが得られるはずである。この様な透明導電性プ ラスチックフィルムは多様な用途展開が可能である。 すでに表面抵抗 $10^{5} \Omega / \mathrm{cm}^{2}$ ，全光線透過率 $85 \%$ のフィ ルムが得られており，透過率を保ったまま表面抵抗 を $10^{3} \Omega / \mathrm{cm}^{2}$ 以下にする事が目標である。また，フッ 素樹脂を原料として用いる事により得られるアモル ファス CNT, カーボンナノウォール, カーボンナ ノホーン，等の実用的に興味深い CNT 類似炭素も 知られている。中でもアモルファス CNT は水素貯 蔵などのエネルギー貯蔵デバイスとしての応用が考 えられる興味深い材料である[8]。

\section{5. ポリアセン型高分子とグラファイト化}

ここでは原材料を選ぶ事によりユニークな炭素・ グラファイト纎維を合成できる例を紹介する。筆者 らはペリレンテトラカルボン酸無水物（PTCDA） を用いてポリアセン型（一次元グラファイト型）高 分子であるポリペリナフタレン（PPN）を合成し， さらに高温熱処理して特異なグラファイトリボンを 作成した[9]。合成は極めて簡単で, 加圧成型した PTCDA のペレットを $\mathrm{Ar}$ 気流中, 赤外線加熱炉で 加熱するだけである。Fig. 1（a）には PTCDA ペレッ ト，（b）には $800^{\circ} \mathrm{C}$ の熱処理によりペレット上に成 長した繊維状生成物の写真を示す。生成物は Fig. 2 に示す様に, 数 $10 \mathrm{~mm}$ の長さと一辺が $0.3 \mu \mathrm{m}$ の四 角な形状を持つ良く成長した繊維状炭素である。 $530^{\circ} \mathrm{C}$ の処理で得られた生成物のレーザーラマンス ペクトルの測定から各吸収のラマンモードが同定さ れ，これにより成長初期には確かにポリペリナフ夕

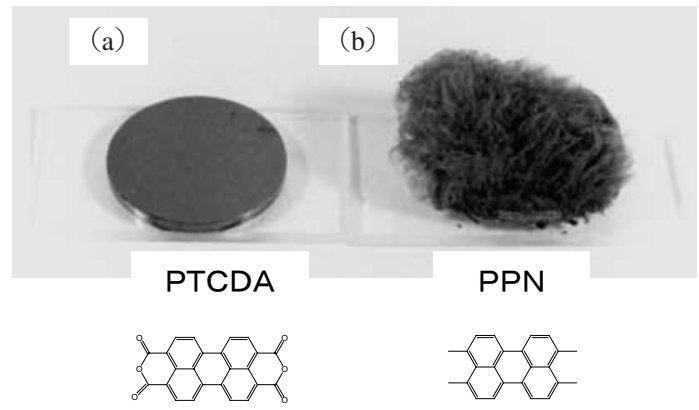

Fig. 1. (a) PTCDA pellet and (b) heat-treated PTCDA pellet at $800^{\circ} \mathrm{C}$ in $\mathrm{Ar}$.
レン構造となっている事が確認されている[10]。こ の様な生成物の形状は成長条件や原料を制御する事 により多様に変化させる事ができる。一例として, Fig. 3 には PTCDA を用いて $\mathrm{Ar} /$ 水素の混合ガス中 で気相成長させたリボン状生成物（a）と，ナフ夕 レンテトラカルボン酸無水物（NTCDA）から得ら れる丸い形状の纎維（b）を示す。

この PPN 高分子を熱処理すると処理温度の上昇 之共に水素脱離し, 炭素化・グラファイト化が進行 する。TEM 観察から，炭素化繊維は基本的にはア モルファスであるが炭素分子は全体としては成長方 向に積み重なっている事が観察された。処理温度が 高くなるに従い分子の積み重なりは顕著になり, $2800^{\circ} \mathrm{C}$ では Fig. 4 に示すようにグラファイトが積み 重なった梯子のような形状のユニークなリボン状グ

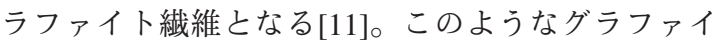

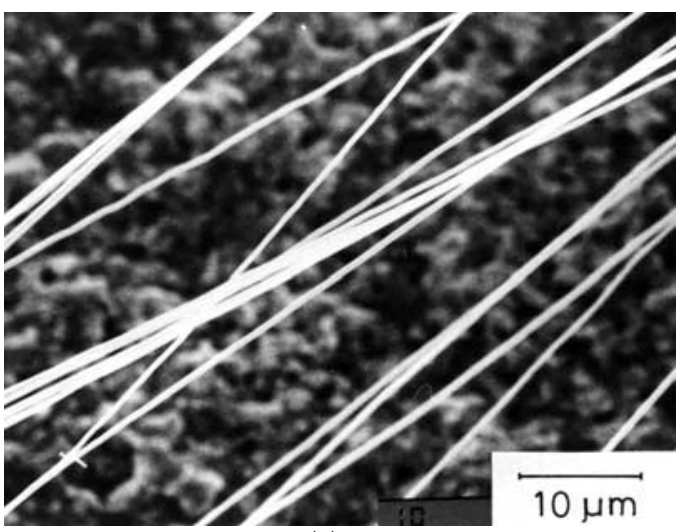

(a)

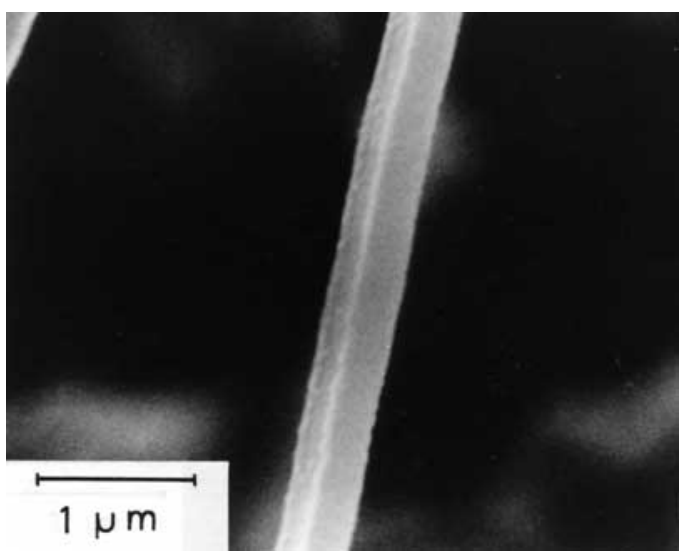

(b)

Fig. 2. (a) SEM feature of the PPN fibers developed on the pellet synthesized in $\mathrm{Ar}$ at $800^{\circ} \mathrm{C}$ and (b) SEM feature of the PPN fiber. 
トリボンは理論的にも興味深く，その物性測定が開 始されている。

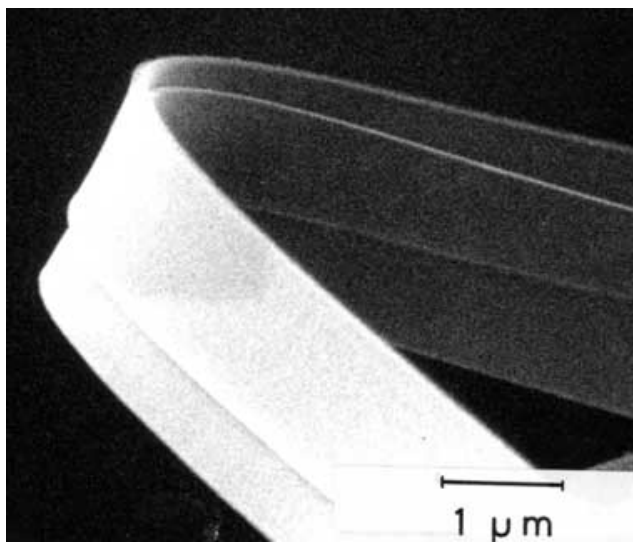

(a)

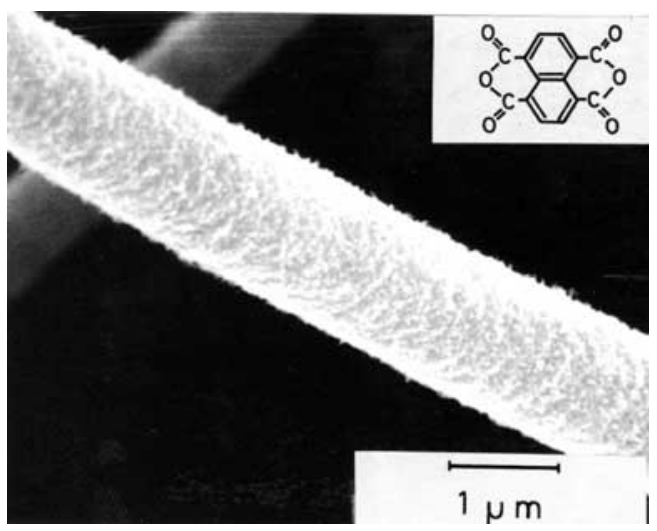

(b)

Fig. 3. SEM feature of the PPN fibers, (a) synthesized from PTCDA in $\mathrm{Ar} / \mathrm{H}_{2}$ at $800^{\circ} \mathrm{C}$, (b) synthesized from NTCDA in Ar at $800^{\circ} \mathrm{C}$.

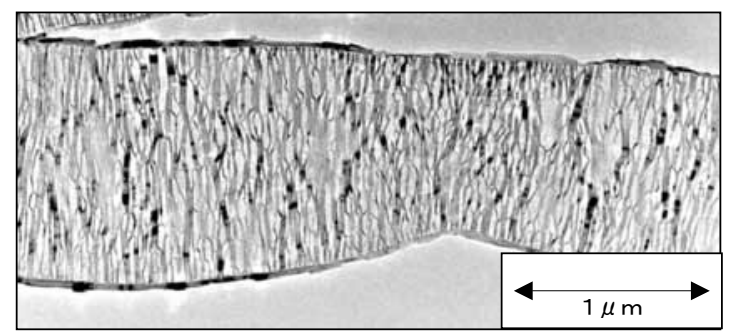

Fig. 4. TEM feature of graphitized PPN fiber $(\mathrm{HTT}=$ $\left.2800^{\circ} \mathrm{C}\right)$.

\section{6. グラフェンの作製と応用}

単層のグラファイトシートであるグラフェンは物 理的に興味ある対象でホットな話題を提供している。 高配向性グラファイトの表面に Electro-phoretic deposition 法でダイヤモンドのナノ粒子を形成し, さらに $1600^{\circ} \mathrm{C}$ で加熱してナノグラフェンが作製さ れている $[12] 。$ 得られたナノグラフェンは炭素数 3000 個，基板との層間は通常のグラファイトより 20〜 50\%大きく，グラフェンが形成されている事が 確認された。この様なナノグラフェンの電子状態は エッジの構造によって大きな影響を受け，エッジが Zigzag 型である場合には，フェルミ準位端に局在 した電子状態を形成し，強磁性などの興味深い物性 の出現が理論的に予測されている $[13,14]$ 。実際 に，榎らは Fig. 5 に示す様に高真空 STM, STS (Scanning tunneling spectroscopy) を用いてナノグラ ファイトの電子状態を測定し， Zigzag 型エッジの 部分でフェルミ準位端に局在した電子状態を輝点 (fermi level at $V s=-30 \mathrm{mV})$ として観察する事に 成功している[15]。

グラフェンはゼロギャップ半導体であり，質量の ないディラック粒子と等価な電子構造を有し，通常 の電子とは異なる伝導特性を示すと予想されている。 グラファイト結晶を壁開した厚さ $3 \mathrm{~nm}$ (グラファ イト 9 層に相当）の試料の伝導度が測定されている が, この様なグラファイトシートは二次元的半金属 に特有な ambipolarな挙動を示し, 電子・ホールの 濃度は $10^{13} / \mathrm{cm}^{2}$, 移動度は $10,000 \mathrm{~cm}^{2} / V s$ であると報

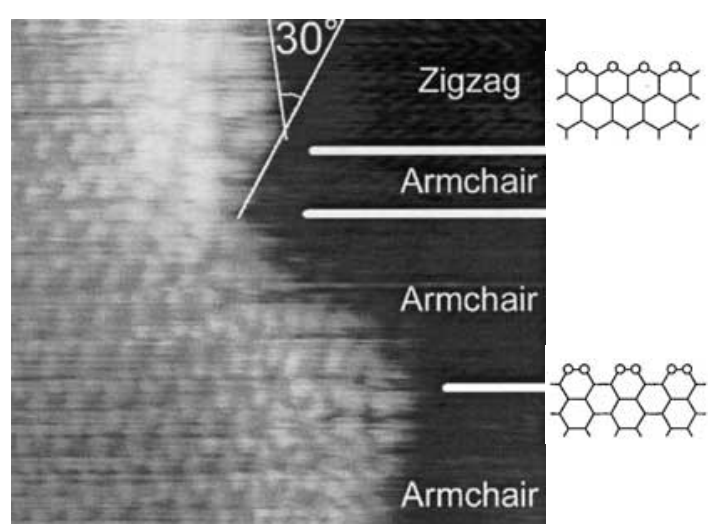

(Reprinted from J. Mater. Chem. 2005, 15, 3999)

Fig. 5. STM image $(9 \mathrm{~nm} \times 9 \mathrm{~nm})$ of a hydrogenterminated nano-graphite edge. The edge states are responsible for the bright spots around the zigzag edge. 
告されている[16]。最近，ついに単層シートの磁気 輸送現象が測定され, 質量ゼロの準粒子の存在が確 かめられた。無磁場における電気抵抗の測定では不 純物量によらない值が得られ，ゼロギャップ半導体 の理論值 $4 e^{2} /(\pi h)$ より大きな值となってい る $[17,18]$ 。このような大きな移動度や特異な準粒 子の存在は, 将来この様な特性を利用した全く新し いデバイスの可能性を示すものである。

\section{7. 高分子からの高品質グラファイトの作製と応用}

高分子フィルムを炭素化する固相からのグラファ イト作製に関する報告は 1987 年になされ，意外に Table 1 に示した 9 種類の炭素作成法の中では一番 新しい。最初の報告から 20 年を経過した現在でも 良質のグラファイトになる高分子としては，ポリイ ミド（PI），ポリオキサジアゾール，ポリパラフェ ニレンビニレンなど数種類が知られているに過ぎな い[19-21］。高分子が良質のグラファイトに転化出 来るためには，(1)分子配向した高分子であり，(2)熱 分解の過程で気化・溶融せず，(3)分解後ただちに再 結合し，(4)分子の配向性を保ったまま炭素化する事， が必要である。

炭素化・グラファイト化の過程は以下の様に進行 する。PI フィルムは $500^{\circ} \mathrm{C}$ 付近で熱分解してその重 量は約 $45 \%$ になり，この時に厚さ・長さは等方的 に収縮する。その後, 重量は徐々に減少するだけで あまり変化しないが, 重量変化のほとんど無い $2000^{\circ} \mathrm{C}$ 以上の領域ではフィルム厚さが薄くなる一方 で面積は増加する。この様な変化は $2000^{\circ} \mathrm{C}$ 付近か ら炭素の再配列が起こり，グラファイト化が進行す る事に対応している。Fig. 6 には得られたグラファ

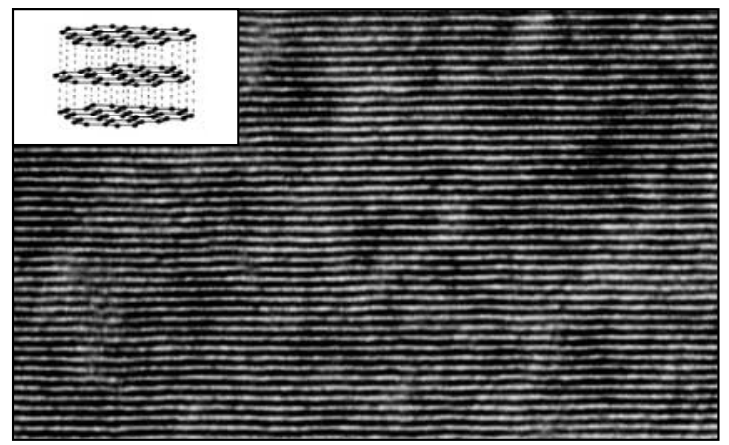

Fig. 6. Lattice image (TEM feature) of the graphite film $\left(\mathrm{HTT}=3000^{\circ} \mathrm{C}\right)$.
イトの断面 TEM 写真を示す。グラファイトの層構 造（層間 $0.3354 \mathrm{~nm}$ ）はきれいに配向しており，極 めて高品質のグラファイトである事が分かる。得ら れるグラファイトの特徵は高品質である事以外に, フィルム状の大面積グラファイトが容易に得られる 事，製造プロセスの制御により柔軟性や強勒性など の機械的性質を自在に制御できる事，などであり工 業的に重要な材料となっている。

Fig. 7 にはPI から得られた柔軟なグラファイトフィ ルムの写真を示す。このフィルムはグラファイト層 を破壊せずに層間の剥離を行った後圧縮する，と言 う方法で製造されるが[22], 従来のグラファイトフィ ルムと比較して機械的強度や電気伝導度等の物性は 10 倍優れている。例えば，熱伝導度は800〜 $1200 \mathrm{~W} / \mathrm{mK}$ でありその值は銅の 2 倍以上である。 この様な性質は携帯電話や小型ゲーム機，あるいは 携帯用パソコンの CPU，チップセット，メモリ等 からの発熱を速やかに拡散するための放熱材料とし て広く使用されている。また，製造条件の制御で得 られる硬質フィルムは世界最高の音速 （19000 m/sec）を有しており，雑音を防ぐための内 部損失が大きい $(\tan \delta=0.02)$, 軽い（比重 $\left.2.1 \mathrm{~g} / \mathrm{cm}^{3}\right)$ ，などの性質を生かしてスピーカー用の ツィータ (高音) 振動板として商品化された。

複数枚のPI フィルム（厚さ $25 \mu \mathrm{m} ）$ を 1000〜 5000 枚積層し，内部にしわやひずみが入らないよ うにしながら加圧下で炭素化・グラファイト化する 方法で，グラファイトブロックが作製される[23]。 例えば $3200^{\circ} \mathrm{C} て ゙$ 作製されたグラファイトの場合, 品質を評価するのに用いられる電気抵抗の温度依存 性 $\left(\sigma_{\mathrm{RT}} / \sigma_{4.2 \mathrm{~K}}\right)$ は 6.0 であり, 最高級のグラファイト

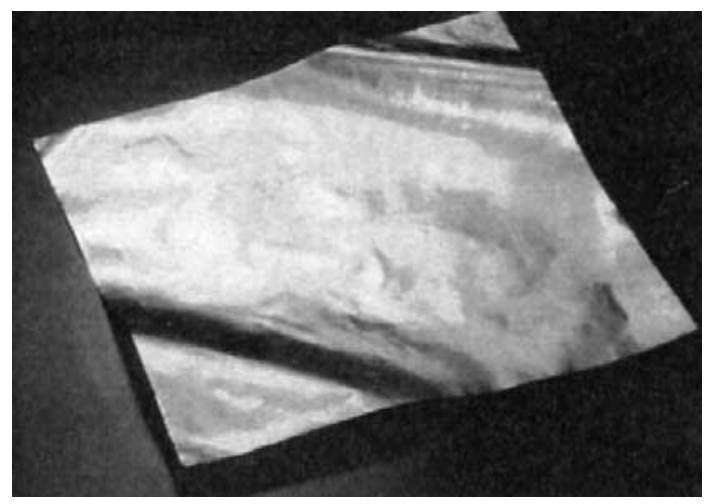

Fig. 7. Flexible graphite sheet obtained from polyimide film $\left(\mathrm{HTT}=2800^{\circ} \mathrm{C}\right)$. 
である事を示している。このブロックはモノクロメー ターとしてX 線回折装置に広く用いられている。 これはグラファイトの（002）X 線回折強度が極め て大きい事を利用して $\mathrm{CuK}_{\alpha}$ 線以外の波長の $\mathrm{X}$ 線を 除去するものであるが，モノクロとして使用するに はグラファイト層が平行である事が必要である。現 在モザイクスプレッド值（MS）が $0.3 \sim 0.4^{\circ}$ の商品 が製造・販売され，X 線回折装置に不可欠な素子と なっている。この方法で得られたブロック （Fig. 8（a)）は高圧力の実験の方々にはなじみ深い 中性子線回折に抢いても, 高次回折線を除去する役 割の中性子線フィルターとして使用されている。最 近，高度な製造技術を駆使してトロイダル型に成型 したグラファイトの X 線集光素子が開発され, 直 接光の 300 倍に達する高強度 X 線が得られた[24]。

Fig. 8（b），(c）には，トロイダル型グラファイトX 線集光素子と集光原理を示す。これはトロイダル型 素子の内面で X 線を全反射し単色化すると同時に 焦点に集光するもので，簡易に強力な X 線を得る 新たな手法として興味深い。

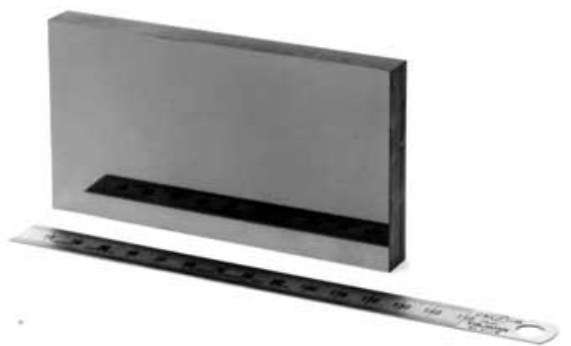

(a)

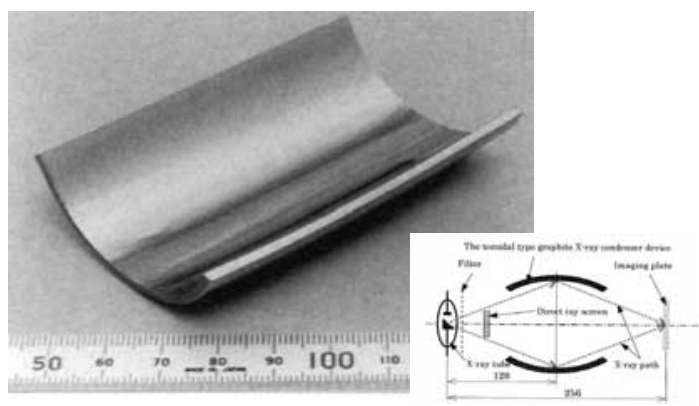

(b)

(c)

Fig. 8. Graphite blocks for radiation optics, (a) neutron filter with $\mathrm{MS}=1.8^{\circ}$ and (b) toroidal type graphite X-ray condenser device (1/3 part of the whole device).

\section{8. ダイヤモンドへの圧力誘起相転移}

ダイヤモンドには良く知られた立方晶以外に六方 晶ダイヤが存在する。立方晶ダイヤが $\mathrm{ABCABC} の$ 積層構造を持つのに対して, グラファイト，六方晶 ダイヤは $\mathrm{ABABAB}$ の積層構造を持つ。従ってグラ ファイト $\Rightarrow$ 立方晶ダイヤ間の相転移には熱と圧力の 両方が必要となるが，グラファイト乡六方晶ダイヤ の間は圧力のみで相転移する。しかし，六方晶ダイ ヤは加圧下では安定に存在するものの常圧・室温で はグラファイトに戻ってしまう。グラファイトの六 方晶ダイヤへの圧力誘起転移に関する報告として, 電気抵抗測定[25], $X$ 線測定[26], 反射率とラマン 測定[27] があり，それらの結果から結晶性のよいグ ラファイトほど，また圧力の一軸性が高いほど低い 圧力で転移すると考えられている。

清水らは前記の高品質グラファイトフィルム（PI の $3000^{\circ} \mathrm{C}$ 処理品）を用いて，ダイヤモンドへの転 移実験を行っている[28]。加圧装置としてダイヤモ ンドアンビルセルを，压力媒体として一軸性の高い （準静水圧）Daphne Oil と，静水圧であると考えら れる He，を用いた。Fig. 9 にはX 線測定の結果を 示す。Daphne Oil の場合六方晶ダイヤとグラファイ 卜の共存する圧力領域は 17〜 $23 \mathrm{GPa}$ であり, $\mathrm{He}$ で は両相の共存する圧力領域は 19〜23 GPa であった。 静水圧でも準静水圧でもグラファイトと六方晶ダイ ヤが共存する圧力領域は過去の報告と比べて極めて
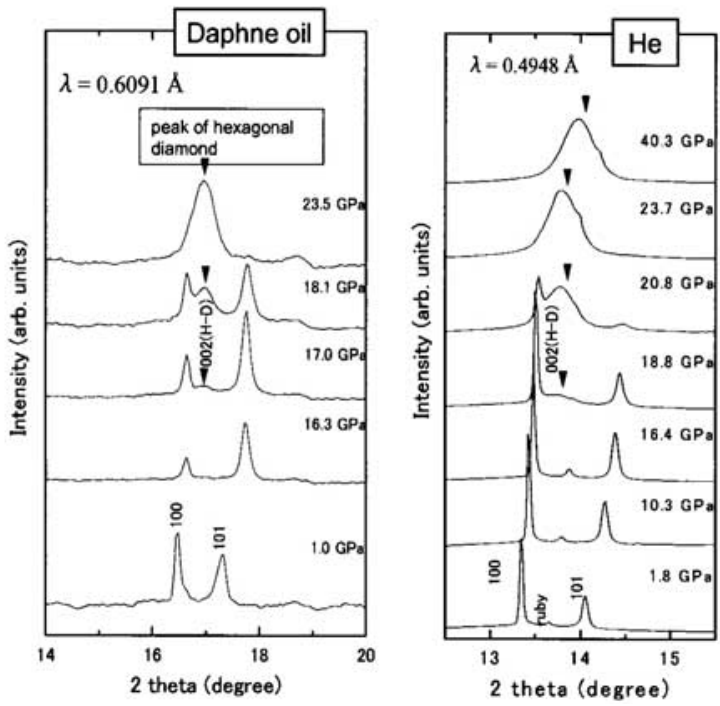

Fig. 9. X-ray diffraction patterns of the graphite film under pressure, (a) in Daphne Oil, (b) in He. 
狭く, 急激に転移が起きると推測できた。試料は圧 力を下げると 5 10 GPa まで透明性を有しているが 常圧では黒色に戻り，ラマン測定からも実際にグラ ファイトに戻っている事が確認された。一方，圧力 下で加熱処理を行うと六方晶ダイヤの一部が立方晶 ダイヤに変換され, 室温で六方晶と立方晶が共存す るダイヤモンドフィルムを取り出す事ができた。こ れはグラファイト $\rightarrow$ 六方晶ダイヤ $\rightarrow$ 立方晶ダイヤの 転移プロセスを明確に示した最初の例であると考え られ，今後の研究の進渉が期待される[29]。

\section{9. おわりに}

本報告ではグラファイト系炭素材料の次元性と言 うキーワードで，その最新動向と応用について述べ た。古くて新しいと言われる炭素材料は出発原料や 作製法の多様化，プロセスの精密制御などで 21 世 紀の素材と言われるにふさわしい内容を備えるに至っ た。中でもグラファイト系材料はその多様な用途展 開のゆえにとりわけ重要な材料となりつつある。高 圧力や超高温による材料合成, 極低温などにおける 物性測定の手段はより高付加価値の炭素材料を得る ための重要な手段であり, 今後その重要性はますま す増加するであろう。

\section{参考文献}

[1] 大谷杉郎: 炭素新時代（ダイヤモンド社, 1987), 第 3 章, p. 77. 記載の表に加筆.

[2] A.El. Goresy, G. Donnay: Science, 164, 363 (1968).

[3] K. Miyazawa, Y. Kuwasaki, A. Obayashi, M. Kuwabara: J. Mater. Res., 17, 83 (2002).

[4] M. Chikamatsu, S. Nagamatsu, Y. Toshida, K. Saito, K. Yase: Appl. Phys. Lett., 87, 203504 (2005).

[5] K. Hata, D.N. Futaba, T. Yamada, K. Mizuno, T. Namai, M. Yumura, S. Iijma: Science, 306, 1362 (2004).

[6] D.N. Futaba, K. Hata, T. Yamada, K. Mizuno, M. Yumura: Phys. Rev. Lett., 95, 056104 (2005).

[7] Y. Maeda, S. Kimura, M. Kanda, Y. Hirashima, T. Hasegawa, T. Wakahara, Y. Lian, T. Nakahodo, T. Tsuchiya, T. Akasaka, J. Lu, X. Zhang, Z. Gao, Y. Yu, S. Nagase, S. Kazaoui, N. Minami, T. Shimizu, H. Tokumoto, R. Saito: J. Am. Chem. Soc., 127, 10287
(2005).

[8] H. Nishino, C. Yamaguchi, H. Nakaoka, R. Nishida: Carbon, 41, 2165 (2003).

[9] M. Murakami: Synth. Met., 18, 531 (1987).

[10] M. Murakami, S. Iijima, S. Yoshimura: J. Appl. Phys., 60, 3856 (1986).

[11] M. Murakami: J. Appl. Phys., 67, 194 (1990).

[12] A.M. Affoune, B.L. Prasad, H. Sato, T. Enoki, Y. Kaburagi, Y. Hishiyama: Chem. Phys. Lett., 17, 348 (2001).

[13] 藤田光考, 若林克法, 伊神正貫, 中田恭子, 草部 浩一: 固体物理, 32, 179 (1997).

[14] 榎敏明: 応用物理, 74, 192 (2005).

[15] T. Enoki, Y. Kobayashi: J. Mater. Chem., 15, 3999 (2005).

[16] K.S. Novoselov, A.K. Gein, S.V. Morozov, D. Jiang, Y. Zhang, S.V. Dubonos, I.V. Grigorieva, A.A. Firsov: Science, 306, 666 (2004).

[17] K.S. Novoselov, A.K. Geim, S.V. Morozov, D. Jiang, M.I. Katsnelson, I.V. Grigorieva, S.V. Dubonos, A.A. Firsov: Nature, 348, 197 (2005).

[18] Y. Zhang, Y-W. Tan, H.L. Stormer, P. Kim: Nature, 348, 201 (2005).

[19] M. Murakami, K. Watanabe, S. Yoshimura: Appl. Phys. Lett., 48, 1594 (1986).

[20] T. Ohnishi, I. Murase, T. Noguchi, M. Hirooka: Synth. Met., 14, 207 (1986).

[21] M. Inagaki, T. Takeichi, Y. Hishiyama, A. Oberlin: Chem. Phys. Carbon, 26, 245 (1999).

[22] 西木直巳, 武弘義, 村上睦明, 吉村進, 吉野勝美: 電学論 A, 123, 1115 (2003).

[23] M. Murakami, N. Nishiki, K. Nakamura, J. Ehara, H. Okada, T. Kouzaki, K. Watanabe, T. Hoshi, S. Yoshimura: Carbon, 30, 255 (1992).

[24] 西木直巳, 川島勉, 村上睦明, 吉村進, 吉野勝美: 電学論 A, 124, 1059 (2004).

[25] F.P. Bundy, J.S. Kasper: J. Chem. Phys., 46, 3437 (1967).

[26] Y.X. Zhao, I.L. Spain: Phys. Rev. B, 40, 993 (1989).

[27] M. Hanfland, K. Syassen, R. Sonnenschein: Phys. Rev. B, 40, 1951 (1989).

[28] 魚留篤, 中本有紀, 加賀山朋子, 清水克哉, 草部 浩一, 西川泰司, 村上睦明, 大石泰生, 綿貫徹: 第 46 回高圧討論会要旨集, 1P20, p. 96 (2005).

[29] 魚留篤, 加賀山朋子, 中本有紀, 清水克哉, 草部 浩一, 西川泰司, 村上睦明, 大石泰生, 綿貫徹: 第 61 回日本物理学会講演要旨集, 30pTE-10, p. 859 (2006).

[2006 年 4 月 28 日受理] 